\title{
Adding a Corticosteroid or Switching to Another Anti-VEGF in Insufficiently Responsive Wet Age-Related Macular Degeneration
}

This article was published in the following Dove Press journal: Clinical Ophthalmology

\author{
Cagdas Kaya' \\ Souska Zandi ${ }^{1,3}$ \\ Isabel B Pfister $\mathbb{D}^{1,2}$ \\ Christin Gerhardt ${ }^{1,2}$ \\ Justus $G$ Garweg $\mathbb{D}^{1,2}$ \\ 'Swiss Eye Institute, Rotkreuz, and \\ Berner Augenklinik am Lindenhofspital, \\ Bern, Switzerland; ${ }^{2}$ Department \\ Ophthalmology, University Hospital Bern, \\ Bern, Switzerland; ${ }^{3}$ Department of \\ Ophthalmology, Inselspital, Bern \\ University Hospital, University of Bern, \\ Bern, Switzerland
}

Purpose: To compare the effect of adding a corticosteroid or switching to another antiVEGF treatment in patients with exudative age-related macular degeneration (eAMD) with persisting intraretinal fluid on anti-VEGF monotherapy.

Methods: This retrospective, interventional case series involved 43 pseudophakic eyes with eAMD and persistent intraretinal fluid on anti-VEGF treatment that switched treatment to a combination of Ozurdex ${ }^{\circledR}$ or Triamcinolone and anti-VEGF therapy (group 1) or to another anti-VEGF agent (group 2). The number of injections, time to re-injection, change in central retinal thickness (CRT), and best-corrected visual acuity (BCVA) from 12 months prior to 12 months after switch to third-line therapy were defined as primary outcomes.

Results: Whereas the treatment demand was reduced (from $8.8 \pm 2.2$ to $4.6 \pm 2.9$ injections; $p=0.001$ ) and the re-injection interval extended in group 1 (from $1.5 \pm 0.4$ months to $4.4 \pm 3.8$ months; $p=0.001$ ), these parameters did not change in group 2 ( $7.4 \pm 1.6$ to $7.3 \pm 2.2 ; p=0.90$ and $1.7 \pm 0.3$ months to $1.9 \pm 0.8$ months; $p=0.75$ ). Mean CRT decreased from $455.7 \pm 30.1$ and 427.6 $\pm 36.0 \mu \mathrm{m}$ (groups 1 and 2, respectively) to $359.1 \pm 38.2$ and $303.1 \pm 44.4 \mu \mathrm{m}$ (intergroup $p=0.03$ ). The mean baseline BCVA of 62.6 \pm 3.8 letters (group 1) and 63.0 \pm 1.9 letters (group 2) remained stable under therapy in both groups (intergroup $p=0.67$ ).

Conclusion: In eyes with eAMD with persistent intraretinal fluid on anti-VEGF monotherapy despite frequent re-injections, corticosteroids achieved a similar functional and morphological outcome over 12 months as switching to another anti-VEGF therapy, but with a reduced injection burden. In selected cases, corticosteroid treatment may thus be an option for third-line therapy in refractory exudative AMD.

Keywords: exudative age-related macular degeneration, Ozurdex, dexamethasone intravitreal implant, triamcinolone, ranibizumab, aflibercept

\section{Introduction}

Treatment failures have been reported in many of the larger randomized clinical trials of wet age-related macular degeneration (AMD) with an incidence of about $10 \%$ within the first year. ${ }^{1,2}$ Additionally, $20-30 \%$ of patients appear to respond insufficiently to treatment; ${ }^{3-5}$ however, the underlying reasons for this remain under debate. ${ }^{6}$

Independent of their response to treatment, the majority of patients will need conBerner Augenklinik am Lindenhofspital, Bremgartenstrasse 119, Bern

$\mathrm{CH}-30 \mathrm{I}$, Switzerland

$\mathrm{Tel}+4|3| 3|I| 222$

Fax +4I 3I 3II 1433

Email Justus.garweg@swiss-eye-

institute.com tinuous active treatment. The intensity of this treatment may be based on individual needs. Even under ideal conditions, long-term decline of visual acuity may occur in response to increasing age and natural progression of the underlying degenerative disease component. Insufficient response to treatment and under-treatment, on the other hand, 
promote the development and progression of atrophy and fibrovascular scarring and also limit the long-term functional prognosis and potential for further improvement. ${ }^{7,8}$

Two anti-vascular endothelial growth factor (anti-VEGF) therapies have been approved for the treatment of active exudative AMD (eAMD). These include Ranibizumab in 2006 and Aflibercept in 2011.9,10 None of these drugs, however, is able to control the progression of fibrovascular scarring and the development of geographic atrophy in the retinal pigment epithelium/choriocapillaris/Bruch's membrane complex, which also affects the neuroretina. ${ }^{11}$ Even worse, these drugs may potentially contribute to more rapid progression of this degenerative process for which currently no drug has proven effective. ${ }^{8,12,13}$ This advocates for a reduction in the use of anti-VEGF drugs to suit the individual needs with the aim of maintaining a dry retina. If the latter is not achieved, the aim should at least be the absence of any intraretinal and stable subretinal and sub-pigment epithelial fluid with the minimum possible number of injections. ${ }^{14}$

Strategies to improve the outcome in cases with an unsatisfactory response to anti-VEGF drugs have been discussed; however, the pathophysiological basis for the limited response has not fully been understood. ${ }^{6}$ The possibility of resistance to anti-VEGF drugs has been suggested, but may be of minor clinical relevance. As AMD has been linked to several independent pathological factors, including chronic oxidative stress, decline of autophagic capacity, and inflammation, ${ }^{15-19}$ many potential targets for treatment are possible. Numerous attempts have been made in recent years to understand and target the inflammatory tissue response which is seen in the development of wet AMD. ${ }^{20-22}$ It is thus surprising that, during the early days of the anti-VEGF era, only a few studies with small case numbers have been published regarding the impact of intravitreal corticosteroids (e.g. triamcinolone, dexamethasone) on disease progression in poor anti-VEGF responders. ${ }^{23-28}$ Few studies have since been reported on the use of steroid treatment for eAMD; most have reported on the use of combination therapy (e.g. steroids with anti-VEGF treatment). ${ }^{29,30}$ In a retrospective, real-world clinical study, we compare combined treatment with corticosteroids and antiVEGF (group 1), including a dexamethasone-based implant $\left(\right.$ Ozurdex ${ }^{\circledR}$ ) or Triamcinolone, or switch to another anti-VEGF agent (group 2) for the treatment of eAMD which has incompletely responded to anti-VEGF drugs.

\section{Patients and Methods}

This retrospective, interventional case series included patients with eAMD who responded insufficiently to prior
anti-VEGF therapy. All patients were treatment naïve before anti-VEGF therapy started and primarily received antiVEGF therapy in treat and extend regime. The decision to switch medication after insufficient response to anti-VEGF therapy was based on persisting intra- and/or subretinal fluid after 12 months of treatment or a dissatisfying treatment demand which did not allow prolongation of injection intervals beyond 6 weeks. Prior to the treatment switch, patients received either Ranibizumab (Lucentis ${ }^{\circledR}$, Novartis) or Aflibercept (Eylea@, Bayer) at (up to) monthly intervals in the previous 12 months. Informed consent for the planned off-label treatment was signed by each participant. Patients with inadequately controlled glaucoma (intraocular pressure $>21 \mathrm{mmHg}$ under therapy with two drugs), clear lens, structural damage to the macula excluding functional gain, retinal detachment, retinal vascular disease (i.e. retinal vein occlusion, central retinal artery occlusion), history of cataract surgery in the previous six months, any posterior segment surgery, history of or ongoing uveitis of possible infectious origin, and any systemic disease potentially interfering with the local situation (i.e. diabetes mellitus with maculopathy) were excluded.

This study was approved by the Institutional Ethics Committee, University of Bern (reference number: 330/14). All patients had given informed consent prior to inclusion in the study for the use of their data, strictly adhering to the tenets of the Declaration of Helsinki.

Group 1 included a consecutive series of eyes that had received either: 1) a $0.7 \mathrm{mg}$ Dexamethasone implant (Ozurdex ${ }^{\circledR}$ Allergan Pharmaceuticals, Westport, Ireland) within 6 weeks of their last anti-VEGF injection or $50 \mu \mathrm{L}$ (corresponding to an estimated equivalent of $4 \mathrm{mg}$ ) of crystalline Triamcinolone acetonide (Kenacort ${ }^{\circledR}$, Dermapharm AG, Huenenberg, Switzerland) after removal of the carrier fluid intravitreally in addition to $50 \mu \mathrm{L}$ of the anti-VEGF drug given prior to the switch in treatment protocol (i.e. Ranibizumab $0.5 \mathrm{mg}$ or Aflibercept $2.0 \mathrm{mg}$ ). The treatment of group 2 eyes was switched to either Ranibizumab $0.5 \mathrm{mg}$ (from initial therapy with Aflibercept $2.0 \mathrm{mg}, \mathrm{n}=6$ ) or Aflibercept $2.0 \mathrm{mg}$ (from initial therapy with Ranibizumab $0.5 \mathrm{mg}, \mathrm{n}=19$ ) within 6 weeks of their last anti-VEGF injection. In the 12 months prior to treatment change, none of the patients had received any other treatment than intravitreal anti-VEGF injection. Criteria for re-injection were in both groups defined as the presence of any intraretinal fluid or instability of subretinal fluid or pigment epithelial detachment. 
Measurements of best-corrected visual acuity (BCVA) and central retinal thickness (CRT) in $\mu \mathrm{m}$, were quantified at the start of therapy, at 3,6, and 12 months of anti-VEGF treatment prior to switch, as well as at the time of treatment switch and 3, 6, and 12 months thereafter. BCVA was performed on a Snellen scale and converted to Early Treatment Diabetic Retinopathy Study (ETDRS)-letter scores with 85 letters representing a BCVA of 1.0. CRT was measured from the inner retinal surface to Bruch's membrane by optical coherence tomography (OCT, Spectralis TM, Heidelberg Engineering, Heidelberg, Germany). Baseline values were defined using data from 12 months prior to treatment switch.

Study endpoints included the number of injections, time to re-injection, change in CRT, and ETDRS letters from 12 months prior to and 12 months after treatment switch. The aim was to assess functional stability/maintenance (maximum ETDRS letter change within \pm 5 ETDRS letters) or improvement (loss or gain of $>5$ ETDRS letters) and anatomical response (anatomic stability $/$ maintenance $=$ max. change in CRT within $\pm 50 \mu \mathrm{m}$; improvement $=\mathrm{CRT}$ reduction $\geq 50 \mu \mathrm{m})$ under therapy.

Numerical data are presented as mean values together with the standard deviation. Nonparametric tests were used to analyze the data as the data were not normally distributed. The Wilcoxon sign-rank test was used to test the change over time within each group, and comparisons between the two groups were analyzed using the Mann-Whitney $U$-test. For comparison of the proportions between the groups a Chi-square test was used. A p-value of $<0.05$ was considered statistically significant.

\section{Results}

Forty-three eyes from 43 patients (18 in group $1(\mathrm{n}=7$ Triamcinolone, $\mathrm{n}=11$ Dexamethasone), 25 in group 2) were included. All eyes were pseudophakic. All eyes had been treated with intravitreal injections of Ranibizumab $0.5 \mathrm{mg}$ or Aflibercept $2.0 \mathrm{mg} 12$ months prior to treatment switch starting with three loading doses. There were no significant differences between the two treatment groups with regard to gender, age, initial BCVA, baseline CRT, and choroidal neovascularization (CNV) type (Table 1). Both groups showed similar proportions of persistent AMD activity (defined as presence of any intraretinal fluid or instability of subretinal fluid or pigment epithelial detachment) from 12 months prior to until 12 months after treatment switch (Table 2).

Also, there was no difference between the two groups in terms of the total number of injections and 12-month average
Table I Baseline Characteristics of Patients with Insufficient Response to Anti-VEGF Monotherapy

\begin{tabular}{|c|c|c|c|}
\hline & Group I & Group 2 & pValues \\
\hline Number of eyes & 18 & 25 & \\
\hline Female (\%) & 61 & 44 & 0.36 \\
\hline Mean age (years) & $81 \pm 9$ & $87 \pm 5$ & 0.07 \\
\hline CNV Type classic (\%) & II & 20 & 0.14 \\
\hline CNV Type occult (\%) & 67 & 64 & \\
\hline CNV Type mixed (\%) & 16 & 16 & \\
\hline Baseline BCVA (ETDRS) & $63 \pm 4$ & $63 \pm 2$ & 0.74 \\
\hline Baseline CRT $(\mu \mathrm{m})$ & $456 \pm 30$ & $428 \pm 36$ & 0.30 \\
\hline
\end{tabular}

Abbreviation: CNV, choroidal neovascularization; BCVA, best-corrected visual acuity; ETDRS, Early Treatment Diabetic Retinopathy Study scores with 85 letters representing a BCVA of I.0; CRT, central retinal thickness.

Table 2 Portion of Eyes with Persistent Disease Activity

\begin{tabular}{|l|l|l|l|l|l|}
\hline \multirow{2}{*}{} & \multicolumn{2}{|l|}{ Group I } & \multicolumn{2}{|c|}{ Group 2 } & \multirow{2}{*}{} \\
\cline { 2 - 5 } & Yes & No & Yes & No & \\
\hline After the loading phase (\%) & 100 & 0 & 80 & 20 & $p=0.06$ \\
6 months after treatment & 94 & 6 & 84 & 16 & $p=0.38$ \\
initiation (\%) & & & & & \\
Prior to switch (\%) & 94 & 6 & 88 & 12 & $p=0.63$ \\
3 months after switch (\%) & 72 & 28 & 68 & 32 & $p=1.00$ \\
6 months after switch (\%) & 66 & 34 & 56 & 44 & $p=0.54$ \\
12 months after switch (\%) & 72 & 28 & 56 & 44 & $p=0.35$ \\
\hline
\end{tabular}

therapy intervals prior to treatment switch. After treatment switch, group 1 required fewer injections than group 2, which resulted in longer therapy intervals (Tables 3 and 4).

Despite the same anti-VEGF treatment regime in both groups in the 12 months prior to treatment switch, the CRT value at 3 and 6 months before switch was higher in group 1 indicating a higher treatment demand in this group. After

Table 3 Comparison Between and Within the Groups Regarding Number of Injections Within the 12 Months Before and 12 Months After Switch

\begin{tabular}{|c|c|c|c|c|}
\hline \multicolumn{5}{|c|}{ Number of Injections Before Switch } \\
\hline & Mean & SD & Range & \multirow[t]{3}{*}{$p=0.051$} \\
\hline Group I & 8.8 & 2.2 & $5-14$ & \\
\hline Group 2 & 7.4 & 1.6 & $5-11$ & \\
\hline \multicolumn{5}{|c|}{ Number of Injections After Switch } \\
\hline & Mean & SD & Range & \multirow[t]{3}{*}{$p=0.005$} \\
\hline Group I * & 4.6 & 2.9 & $1-10$ & \\
\hline Group $2 *$ & 7.3 & 2.2 & $3-10$ & \\
\hline
\end{tabular}

Notes: *Statistical comparison within the groups (group I: $p=0.001$; group 2: $p=0.90$ ). Abbreviation: SD, standard deviation. 
Table 4 Comparison Between and Within the Groups Regarding Interval of 12 Months Before and 12 Months After Switch

\begin{tabular}{|c|c|c|c|c|}
\hline \multicolumn{5}{|c|}{ Interval in Months Before Switch } \\
\hline & Mean & SD & Range & \multirow[t]{3}{*}{$p=0.05 I$} \\
\hline Group I & 1.5 & 0.4 & I-2.4 & \\
\hline Group 2 & 1.7 & 0.3 & I.I-2.4 & \\
\hline \multicolumn{5}{|c|}{ Interval in Months After Switch } \\
\hline & Mean & SD & Range & \multirow[t]{3}{*}{$p=0.006$} \\
\hline Group I* & 4.4 & 3.8 & $1.2-12$ & \\
\hline Group $2 *$ & 1.9 & 0.8 & I.2-4 & \\
\hline
\end{tabular}

Notes: $*$ Statistical comparison within the groups (group I: $p=0.00$ I; group 2: $p=0.750$ ). Abbreviation: SD, standard deviation.

switch, the two groups showed no difference in CRT at 3 and 6 months. The CRT was however higher in group 1 at 12 months post-switch (Figure 1). There was no difference in the time between the last injection and 12-month follow-up (group 1: $2.5 \pm 1.3$, group 2: $1.9 \pm 0.6$ months, $p=0.12$ ).

There was no difference in BCVA between the groups during the entire study period (Figure 2). There was also no difference in BCVA within group 1 (between patients treated with Triamcinolone and Dexamethasone). There were no adverse events recorded during the study period apart from three cases in group 1 with a rise in intraocular pressure (IOP) following the Dexamethasone implant. All of these cases were treated with additional anti-glaucoma drugs.

\section{Discussion}

Despite effective and well-established therapy with antiVEGF for wet AMD, the proportion patients (20-30\%) with an incomplete response or that require a high demand of anti-VEGF treatment results in a substantial burden to patients, physicians, and care givers. ${ }^{27-29}$ Different therapeutic strategies in these challenging cases, including a switch to another anti-VEGF agent, use of corticosteroids, or use of photodynamic therapy (PDT), remain as third-line therapy options. $^{30-35}$ To the best of our knowledge, a switch to another anti-VEGF agent is the first and most practical strategy to poor response. However, the burden increases further if this strategy also fails. In these cases, corticosteroids may be an interesting option. At the level of Bruch's membrane, an accumulation of inflammatory molecules, recruitment of macrophages, complement activation, increased VEGF

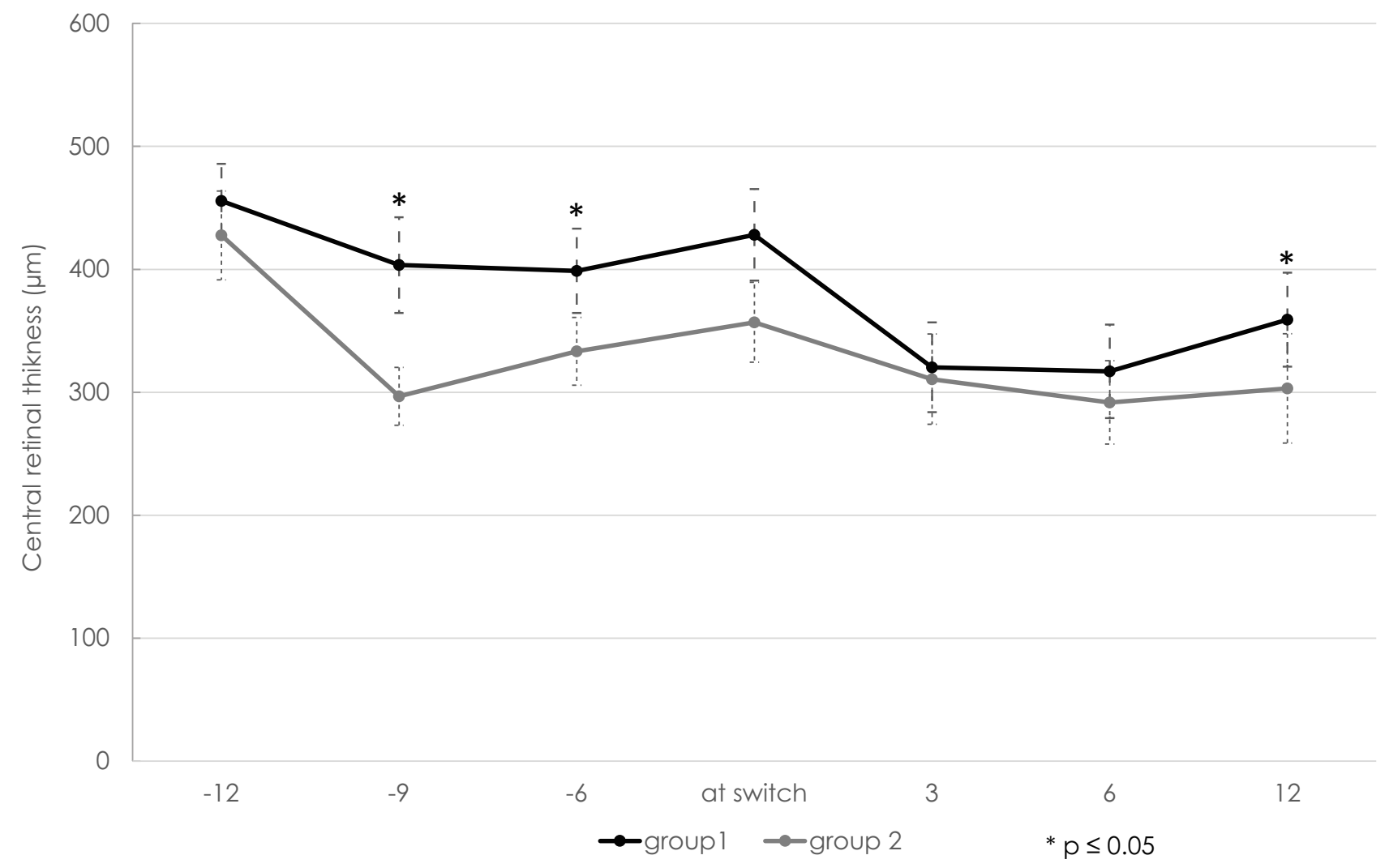

Figure I Central retinal thickness (CRT in $\mu \mathrm{m}$ ) at the start of treatment, 3 months, 6 months, I2 months as well as 3, 6, and I2 months after switch. Black line: group I $\left(n=25\right.$ eyes in 25 patients); grey line: group 2 ( $n=25$ eyes in 25 patients); ${ }^{*} p \leq 0.05$. Error bars represent the standard error of the mean (SEM). 


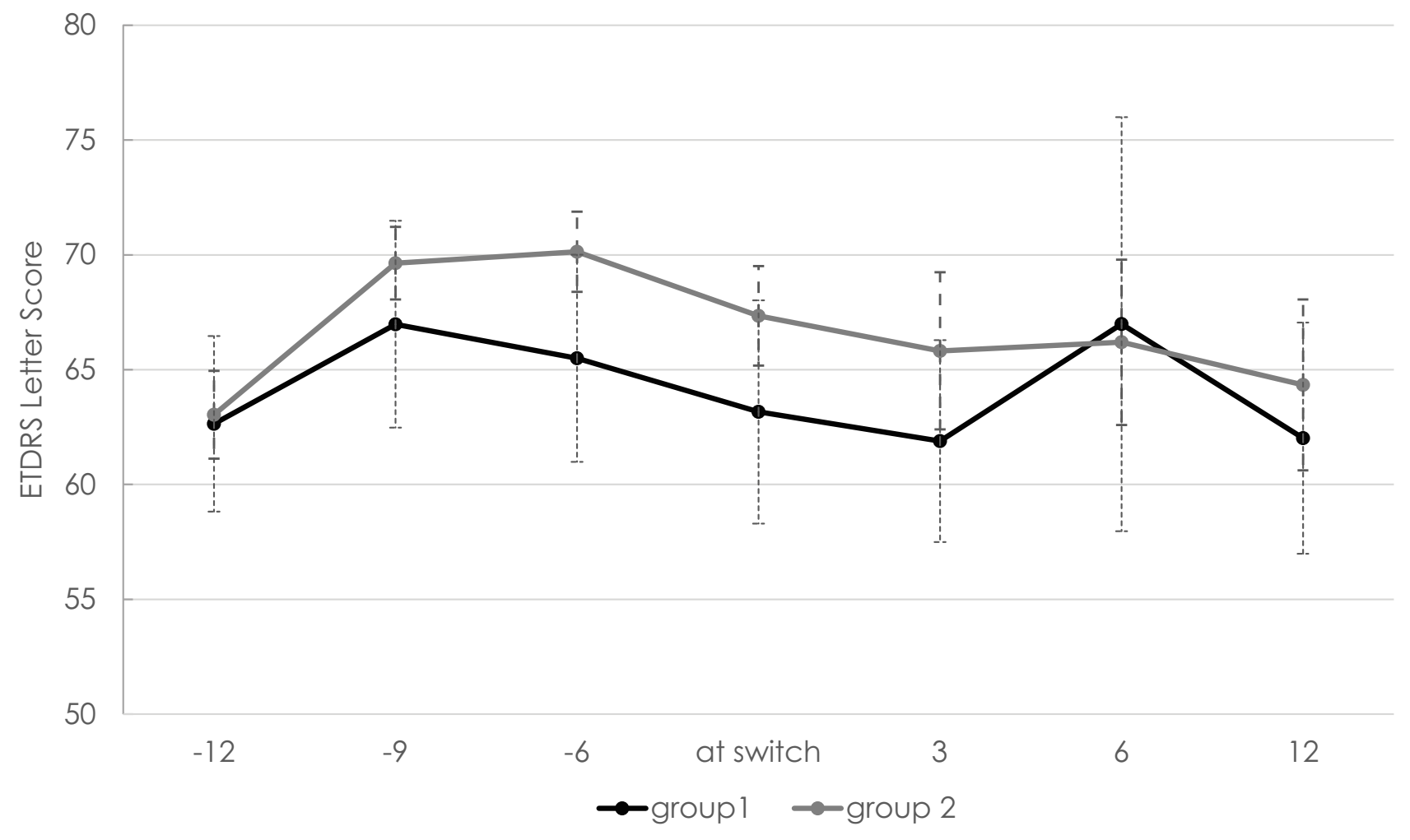

Figure 2 Best-corrected visual acuity (BCVA in EDTRS letters) at start of treatment, 3 months, 6 months, I2 months as well as 3, 6, and I2 months after switch. Black line: group I ( $n=25$ eyes in 25 patients); grey line: group 2 ( $n=25$ eyes in 25 patients). Error bars represent the standard error of the mean (SEM).

expression in the retinal pigment epithelium, microglial activation, and accumulation of cellular debris all contribute to the progression of AMD and its switch to the neovascular form. ${ }^{36-39}$ All the aforementioned factors may be influenced by corticosteroids. Additionally, corticosteroids may affect the endothelial cells by regulating tight junction proteins and limiting VEGF expression through glucocorticoid receptor activity. ${ }^{40,41}$

Our retrospective data suggest that corticosteroid therapy in combination with anti-VEGF treatment is effective in maintaining visual function for three to twelve months in eyes that have not achieved functional and anatomic stability under anti-VEGF monotherapy. This confirms the findings reported in other studies. ${ }^{42-47}$ In these difficult-to-treat, widely unresponsive cases, the need for anti-VEGF injections was reduced significantly by the addition of corticosteroids. This resulted in extension of the re-injection interval while BCVA was kept stable as compared to treatment with intensive anti-VEGF monotherapy. Thus, the desired treatment effect of reducing the treatment burden met the expectation of the treating physicians and patients. However, despite not being significant, an influence of the higher pre-switch injection load in group 1 is questionable.
Furthermore, the higher CRT values seen in group 1 after the loading phase and the first 6 months of antiVEGF treatment indicate that the corticosteroid group may include cases with an even higher treatment demand. The difference at 12 months post-switch may be related to the larger therapy interval extension in group 1 .

If a dry macula has not been achieved within 6 months of treatment initiation, it is conceivable that the treatment effect would have exceeded than that found in our study. ${ }^{48}$ Based on careful case selection, triple therapy, including corticosteroid, anti-VEGF drugs, and photodynamic therapy with Verteporfin $^{\circledR}$, was also suggested to improve outcomes based on the maintenance of the macular structure. ${ }^{35}$ These data indicate that VEGF may not be the only driver of this biologically complex macular disease resulting in macular scarring and atrophy.

Our results support recent findings that pseudophakic eyes with a high treatment demand or that incompletely respond to anti-VEGF treatment may benefit from combined corticosteroid and anti-VEGF treatment in order to maintain function over a period of at least 12 months with a remarkably reduced treatment burden. ${ }^{42-47}$ Whether the outcomes reported herein can be sustained 
for a longer period of time should be addressed in larger series. The interpretation of corticosteroid treatment outcomes in our series has to be undertaken with care based on our rather strict patient selection criteria resulting in a relatively small sample size. Generally, and namely in patients with instable neovascular AMD, the use of corticosteroids is limited by their side effects, namely uncontrolled rise in intraocular pressure and cataract progression.

In conclusion, single patients with an extremely high anti-VEGF treatment demand over longer periods may benefit from an attempt to use corticosteroids in order to control co-existing inflammatory tissue responses in the absence of contraindications for their use.

\section{Ethical Approval}

All procedures performed in studies involving human participants were in accordance with the ethical standards of the institutional and/or national research committee and with the 1964 Helsinki declaration and its later amendments or comparable ethical standards.

\section{Informed Consent}

Informed consent was obtained from all individual participants included in the study.

\section{Disclosure}

JGG acts as advisor for Alcon, Novartis, Bayer, Allergan, outside the submitted work; and contributes to several clinical studies. The underlying manuscript is independent of these activities. The author did not receive direct or indirect support for this study and does not have conflicting interests with the data that are presented herein. None of the other authors report any potential conflict of interest.

\section{References}

1. Rosenfeld PJ, Brown DM, Heier JS, et al. Ranibizumab for neovascular age-related macular degeneration. $N$ Engl $J$ Med. 2006;355:1419-1431. doi:10.1056/NEJMoa054481

2. Brown DM, Michels M, Kaiser PK, et al. Ranibizumab versus verteporfin photodinamic therapy for neovascular age-related macular degeneration: two-year results of the ANCHOR study. Ophthalmology. 2009;116:57-65. doi:10.1016/j.ophtha.2008.10.018

3. Boyer DS, Antoszyk AN, Awh CC, Bhisitkul RB, Shapiro H, Acharya NR. Subgroup analysis of the MARINA study of ranibizumab in neovascular age-related macular degeneration. Ophthalmology. 2007;114:246-252. doi:10.1016/j.ophtha.2006.10.045

4. Heier JS, Brown DM, Chong V, et al.; VIEW 1 and VIEW 2 Study Groups. Intravitreal aflibercept (VEGF trap-eye) in wet age-related macular degeneration. Ophthalmology. 2012;119:2537-2548. doi:10.1016/j.ophtha. 2012.09.006
5. Wykoff CC, Brown DM, Maldonado ME, Croft DE. Aflibercept treatment for patients with exudative age-related macular degeneration who were incomplete responders to multiple ranibizumab injections (TURF trial). Br J Ophthalmol. 2014;98:951-955. doi:10.1136/ bjophthalmol-2013-304736

6. Tranos P, Vacalis A, Asteriadis S, et al. Resistance to antivascular endothelial growth factor treatment in age-related macular degeneration. Drug Des Devel Ther. 2013;7:485-490. doi:10.2147/DDDT.S43470

7. Rasmussen A, Sander B. Long-term longitudinal study of patients treated with ranibizumab for neovascular age-related macular degeneration. Curr Opin Ophthalmol. 2014;25:158-163. doi:10.1097/ ICU.0000000000000050

8. Garweg JG. Makula-Atrophie bei feuchter altersabhängiger Makuladegeneration - unausweichliche folge der anti-VEGF-therapie? Ophthalmologe. 2016;113:1036-1045. doi:10.1007/s00347-016-0306-9

9. Yazdi MH, Faramarzi MA, Nikfar S, Falavarjani KG, Abdollahi M. Ranibizumab and aflibercept for the treatment of wet age-related macular degeneration. Expert Opin Biol Ther. 2015;16:1-10. doi: $10.1517 / 14712598.2015 .1075000$

10. Verner-Cole EA, Davis SJ, Lauer AK. Aflibercept for the treatment of neovascular age-related macular degeneration. Drugs Today (Barc). 2012;48:317-329. doi:10.1358/dot.2012.48.5.1805931

11. Biesemeier A, Taubitz T, Julien S, Yoeruek E, Schraermeyer U. Choriocapillaris breakdown precedes retinal degeneration in age-related macular degeneration. Neurobiol Aging. 2014;35 (11):2562-2573. doi:10.1016/j.neurobiolaging.2014.05.003

12. Maguire MG, Martin DF, Ying GS, et al.; Comparison of Age-related Macular Degeneration Treatments Trials (CATT) Research Group. Fiveyear outcomes with anti-vascular endothelial growth factor treatment of neovascular age-related macular degeneration: the comparison of age-related macular degeneration treatments trials. Ophthalmology. 2016;123:1751-1761. doi:10.1016/j.ophtha.2016.03.045

13. Bhisitkul RB, Desai SJ, Boyer DS, Sadda SR, Zhang K. Fellow eye comparisons for 7-year outcomes in ranibizumab-treated AMD subjects from ANCHOR, MARINA, and HORIZON (SEVEN-UP study). Ophthalmology. 2016;123:1269-1277. doi:10.1016/j.ophtha.2016.01.033

14. Villegas VM, Aranguren LA, Kovach JL, Schwartz SG, Flynn HW Jr. Current advances in the treatment of neovascular age-related macular degeneration. Expert Opin Drug Deliv. 2017;14(2):273-282. doi:10.10 80/17425247.2016.1213240

15. Kauppinen A, Paterno JJ, Blasiak J, Salminen A, Kaarniranta K. Inflammation and its role in age-related macular degeneration. Cell Mol Life Sci. 2016;73:1765-1786.

16. Jarrett SG, Boulton ME. Consequences of oxidative stress in age-related macular degeneration. Mol Aspects Med. 2012;33:399-417. doi:10.1016/ j.mam.2012.03.009

17. Ambati J, Atkinson JP, Gelfand BD. Immunology of age-related macular degeneration. Nat Rev Immunol. 2013;13:438-451. doi:10.1038/nri3459

18. Ferrington DA, Sinha D, Kaarniranta K. Defects in retinal pigment epithelial cell proteolysis and the pathology associated with age-related macular degeneration. Prog Retin Eye Res. 2016;51:69-89. doi:10.1016/j. preteyeres.2015.09.002

19. Zandi S, Nakao S, Chun KH, et al. ROCK-isoform-specific polarization of macrophages associated with age-related macular degeneration. Cell Rep. 2015;10(7):1173-1186. doi:10.1016/j.celrep.2015.01.050

20. Spindler J, Zandi S, Pfister IB, Gerhardt C, Garweg JG. Cytokine profiles in the aqueous humor and serum of patients with dry and treated wet age-related macular degeneration. PLoS One. 2018;13(8): e0203337. doi:10.1371/journal.pone. 0203337

21. Campbell M, Doyle SL. An eye on the future of inflammasomes and drug development in AMD. J Mol Med (Berl). 2013;91:1059-1070. doi:10.1007/s00109-013-1050-0

22. Rezar-Dreindl S, Sacu S, Eibenberger K, et al. The intraocular cytokine profile and therapeutic response in persistent neovascular age-related macular degeneration. Invest Ophthalmol Vis Sci. 2016;57:4144-4150. doi:10.1167/iovs.16-19772 
23. Augustin AJ, Puls S, Offermann I. Triple therapy for choroidal neovascularization due to age-related macular degeneration: verteporfin PDT, bevacizumab, and dexamethasone. Retina. 2007;27 (2):133-140. doi:10.1097/IAE.0b013e3180323de7

24. Conti SM, Kertes PJ. The use of intravitreal corticosteroids, evidence-based and otherwise. Curr Opin Ophthalmol. 2006;17:235-244. doi:10.1097/01.icu.0000193107.00089.ee

25. Gopal L, Sharma T. Use of intravitreal injection of triamcinolone acetonide in the treatment of age-related macular degeneration. Indian J Ophthalmol. 2007;55:431-435. doi:10.4103/0301-4738.36477

26. Jonas JB. Intravitreal triamcinolone acetonide: a change in a paradigm. Ophthalmic Res. 2006;38:218-245. doi:10.1159/000093796

27. Oliver A, Ciulla TA. Corticosteroids as antiangiogenic agents. Ophthalmol Clin North Am. 2006;19:345-351. doi:10.1016/j.ohc.2006 05.002

28. Spaide RF, Sorenson J, Maranan L. Combined photodynamic therapy and intravitreal triamcinolone for nonsubfoveal choroidal neovascularization. Retina. 2005;25:685-690. doi:10.1097/00006982200509000-00001

29. Lim JI, Niec M, Wong V. One year results of a phase 1 study of the safety and tolerability of combination therapy using sustained release intravitreal triamcinolone acetonide and ranibizumab for subfoveal neovascular AMD. Br J Ophthalmol. 2015;99:618-623. doi:10.1136/ bjophthalmol-2014-306002

30. Chaudhary V, Barbosa J, Lam WC, Mak M, Mavrikakis E, Mohaghegh PSM. Ozurdex in age-related macular degeneration as adjunct to ranibizumab (the OARA study). Can J Ophthalmol. 2016;51:302-305. doi:10.1016/j.jcjo.2016.04.020

31. Lux A, Llacer H, Heussen FM, Joussen AM. Non-responders to bevacizumab (Avastin) therapy of choroidal neovascular lesions. $\mathrm{Br}$ J Ophthalmol. 2007;91:1318-1322. doi:10.1136/bjo.2006.113902

32. Gasperini JL, Fawzi AA, Khondkaryan A, et al. Bevacizumab and ranibizumab tachyphylaxis in the treatment of choroidal neovascularisation. Br J Ophthalmol. 2012;96:14-20. doi:10.1136/bjo.2011.204685

33. Forooghian F, Cukras C, Meyerle CB, Chew EY, Wong WT. Tachyphylaxis after intravitreal bevacizumab for exudative age-related macular degeneration. Retina. 2009;29:723-731. doi:10.1097/IAE.0b 013e3181a2c1c3

34. Chang AA, Li H, Broadhead GK, et al. Intravitreal aflibercept for treatment-resistant neovascular age-related macular degeneration. Ophthalmology. 2014;121:188-192. doi:10.1016/j.ophtha.2013.08.035

35. Forte R, Bonavolonta P, Benayoun Y, Adenis JP, Robert PY. Intravitreal ranibizumab and bevacizumab in combination with full-fluence verteporfin therapy and dexamethasone for exudative age-related macular degeneration. Ophthalmic Res. 2011;45 (3):129-134. doi:10.1159/000318877

36. Tuo J, Grob S, Zhang K, Chan CC. Genetics of immunological and inflammatory components in age-related macular degeneration. Ocul Immunol Inflamm. 2012;20:27-36. doi:10.3109/09273948.2011. 628432
37. Nozaki M, Raisler BJ, Sakurai E, et al. Drusen complement components C3a and C5a promote choroidal neovascularization. Proc Natl Acad Sci U S A. 2006;103:2328-2333. doi:10.1073/pnas.0408835103

38. Machalinska A, Dziedziejko V, Mozolewska-Piotrowska K, et al. Elevated plasma levels of C3a complement compound in the exudative form of age-related macular degeneration. Ophthalmic Res. 2009;42:54-59. doi:10.1159/000219686

39. Felinski EA, Antonetti DA. Glucocorticoid regulation of endothelial cell tight junction gene expression: novel treatments for diabetic retinopathy. Curr Eye Res. 2005;30:949-957. doi:10.1080/ 02713680500263598

40. Druilhe A, Letuve S, Pretolani M. Glucocorticoid-induced apoptosis in human eosinophils: mechanisms of action. Apoptosis. 2003;8:481-495. doi:10.1023/A:1025590308147

41. Spitzer MS, Yoeruek E, Kaczmarek RT, et al. Sodium hyaluronate gels as a drug-release system for corticosteroids: release kinetics and antiproliferative potential for glaucoma surgery. Acta Ophthalmol. 2008;86:842-848. doi:10.1111/j.1755-3768.2007.01149.x

42. Calvo P, Ferreras A, Al Adel F, Wang Y, Brent MH. Dexamethasone intravitreal implant as adjunct therapy for patients with wet age-related macular degeneration with incomplete response to ranibizumab. $\mathrm{Br} J$ Ophthalmol. 2015;99:723-726. doi:10.1136/ bjophthalmol-2014-305684

43. Bonfiglio V, Reibaldi M, Fallico M, et al. Widening use of dexamethasone implant for the treatment of macular edema. Drug Des Devel Ther. 2017;11:2359-2372. doi:10.2147/DDDT

44. Todorich B, Thanos A, Yonekawa Y, et al. Simultaneous dexamethasone intravitreal implant and anti-VEGF therapy for neovascular age-related macular degeneration resistant to anti-VEGF monotherapy. J Vitreoretin Dis. 2017;1(1):65-74. doi:10.1177/ 2474126416683299

45. Vakalis N, Echiadis G, Pervena A, et al. Intravitreal combination of dexamethasone sodium phosphate and bevacizumab in the treatment of exudative AMD. Sci Rep. 2015;27(5):8627. doi:10.1038/srep08 627

46. Dhalla MS, Shah GK, Blinder KJ, et al. Combined photodynamic therapy with verteporfin and intravitreal bevacizumab for choroidal neovascularization in age-related macular degeneration. Retina. 2006;26:988-993. doi:10.1097/01.iae.0000247164.70376.91

47. Kuppermann BD, Goldstein M, Maturi RK, et al. Dexamethasone intravitreal implant as adjunctive therapy to ranibizumab in neovascular age-related macular degeneration: a multicenter randomized controlled trial. Ophthalmologica. 2015;234(1):40-54. doi:10.1159/ 000381865

48. Krebs I, Glittenberg C, Ansari-Shahrezaei S, et al. Non-responders to treatment with antagonists of vascular endothelial growth factor in age-related macular degeneration. Br J Ophthalmol. 2013;97:1443-1446. doi:10.1136/bjophthalmol-2013-303513
Clinical Ophthalmology

\section{Publish your work in this journal}

Clinical Ophthalmology is an international, peer-reviewed journal covering all subspecialties within ophthalmology. Key topics include: Optometry; Visual science; Pharmacology and drug therapy in eye diseases; Basic Sciences; Primary and Secondary eye care; Patient Safety and Quality of Care Improvements. This journal is indexed on PubMed
Central and CAS, and is the official journal of The Society of Clinical Ophthalmology (SCO). The manuscript management system is completely online and includes a very quick and fair peer-review system, which is all easy to use. Visit http://www.dovepress.com/ testimonials.php to read real quotes from published authors. 